\title{
Are Moving Average Trading Rules Profitable? Evidence From The Mexican Stock Market
}

\author{
Massoud Metghalchi, (E-mail: metghalchim@uhv.edu), University of Houston, Victoria \\ Xavier Garza-Gomez, University of Houston, Victoria \\ Yong Glasure, University of Houston, Victoria \\ Yung-Ho Chang, Tunghai University, Taiwan
}

\begin{abstract}
This paper tests three moving average technical trading rules for the Mexican Stock Market. Results indicate that moving average rules do indeed have predictive power and can discern recurring-price patterns for profitable trading and support the hypothesis that technical trading rules can outperform the buy-and-hold strategy. Break-even one-way trading costs are estimated to be in the range of $1 \%$ to $3 \%$ over the period under consideration. These break-even costs, we believe, are large compared to recent estimates of actual trading costs, implying that moving average trading rules have predictive power and can generate consistent profits even after transaction costs are considered.
\end{abstract}

Keywords: Technical trading rules, Mexican stock market

\section{Introduction}

Fama (1970) defines an efficient financial market as one in which security prices always fully reflect available information. Any new information quickly and instantaneously is reflected in prices. Moreover, since news on any company, by definition, is unpredictable (arrives randomly), price changes are thereby unpredictable or follow a random walk. The "weak-form" Efficient Market Hypothesis (EMH) asserts that stock prices already reflect all information that can be derived by investigating market trading data such as the history of past prices or trading volume. Advocates of weak-form market efficiency hypothesize that investors cannot drive profits above a buy-and-hold strategy using any trading rule that depends solely on past market information such as price or volume, implying that technical trading rules are useless.

After more than three decades of research and literally thousands of journal articles, financial economists and practitioners have not yet reached a consensus whether technical trading rules can discern recurring-price patterns for profitable trading. The overwhelming majority of financial economists subscribe to the "weak-form" efficient market hypothesis, mainly because of much earlier research that supported the random walk hypothesis. Fama (1965) finds that stock prices indeed follow random walks and that there is no systematic evidence of profitability of technical trading strategies. Van Horn and Parker (1967) using a simple technical trading rule for 30 NYSE securities confirm the random walk hypothesis, while Jensen and Benington (1970) conclude that technical trading rules are not useful. Other studies that supported the weak-form market efficiency in that period include Larson (1960), Osborne (1962), Alexander (1964); Granger and Morgenstern (1963), Mandelbrot (1963), and Fama and Blume (1966). In general, by the end of the 1970s, academics basically rejected technical trading. Shleifer (2000, p. 9) clearly shows this point: "As matters stood at the end of the 1970s, the EMH was indeed one of the great triumphs of twentieth-century economics."

Since the early1990s, technical trading, however, has been enjoying a renaissance both on Wall Street and in academic circles. Several papers have presented evidence that some simple trading rules are useful for predicting 
stock market returns. The cornerstone of this new research on technical analysis is the work of Brock, Lakonishok and LeBaron (1992, BLL hereafter), who analyzed moving averages and trading range breakouts on the Dow Jones Industrial Index from 1897 to 1985 . Their work tests long moving averages of 50,150 and 200 days with short averages of 1, 2 and 5 days using various short and long moving averages of prices to generate buy and sell signals. Drawing from their study, (BLL, P. 1738) point out that "all buy-sell differences are positive and the t-tests for these differences are highly significant..." and conclude that their "results are consistent with technical rules having predictive power, P. 1758". Other researchers have used some variants of BLL's moving averages to investigate whether stock market indices can be predicted with some simple form of technical analysis. Bessembinder and Chan (1995) conclude that BLL's rules are successful in predicting stock price movement in Japan, Hong Kong, South Korea, Malaysia, Thailand and Taiwan, with the predictability strongest in the last three markets. Raj and Thurston (1996) using both the moving average rules and trading range breakout for Hang Seng Futures Index conclude that the moving average strategy did not produce significant excess return, but trading range breakout rules produced significant positive returns for the buy signal. Ergul, Holmes and Priestley (1997), using daily closing prices of 63 stocks traded on the Istanbul Stock Exchange, conclude that technical analysis on volume can aid the prediction of returns which cannot be predicted by the analysis of past returns in isolation. Pruitt and White (1998), using the University of Chicago's CRSP daily data tapes over the 1976-1985 period, conclude that technical trading rules are capable of outperforming a simple buy-and-hold strategy even adjusting for transaction costs. Bessembinder and Chan (1998) confirm the basic BLL results; however, they argue that the BLL results can coexist with the notion of market efficiency when considering transaction costs. Fong and Ho (2001) use technical trading rules for internet stock and conclude that average buy-sell spread is large and significant even after accounting for transaction costs. Gencay (1998a, 1998b) and Ratner and Leal (1999) also support the predictive power of technical trading rules. Kwon and Kish (2002), applying three popular technical trading rules to the NYSE index over the period $1962-$ 1996, conclude that the technical trading rules have the potential to capture profit opportunities over various models when compared to the buy-and-hold strategy.

On the other hand, there are studies that do not support technical strategies. Hudson, Dempsey and Keasey (1996) apply BLL's technical trading rules in the United Kingdom stock market return over the 1935-1994 period and conclude that technical trading rules did not generate excess returns after taking transaction costs of 1 percent per round trip. Szakmary, Davidson, and Schwarz (1999) find that trading rules on individual stocks perform poorly, but trading rules for the overall Nasdaq index tend to earn statistically significant abnormal return; however, they believe that since there is a high level of transaction costs associated with Nasdaq trading, these abnormal returns generally are not economically significant for them. Coutts and Cheung (2000) analyze the Hang Seng returns from 1985 to 1997 and conclude that both the moving average and trading breakout rules fail to provide positive abnormal returns, net of transaction costs. Ready (2002) points out the apparent success of the BLL moving average rules is a spurious result of data snooping and need not persist in the future. Technical trading rules have also been applied to foreign exchange markets. For those who are interested in technical trading on foreign exchange market, Taylor and Allen (1992) and Maillet and Michel (2000) provide an excellent survey.

In this paper we investigate the profitability of some moving average trading rules in the Mexican Stock Market. If we can find some form of moving average rules that can predict changes in the Mexico's Stock Index (IPC), and then identify a trading strategy that will beat the buy-and-hold strategy, we can then assert that moving average rules are useful for predicting future stock market prices. This paper provides such empirical evidence by evaluating several technical trading rules on the Mexican stock market in an attempt to shed additional light on this controversy. Robustness of our findings is further evaluated using a test for Superior Predictive Ability (SPA) developed by Hansen (2005).

The plan of the paper is as follows. Section II discusses data and methodology, while section III presents empirical results on technical trading rules. Section IV compares various strategies with the buy-and-hold strategy, section V shows robustness results, and section VI concludes the paper. 


\section{Data And Methodology}

We use Datastream's daily closing level of the IPC index, an index constructed with the 35 most liquid stocks listed in the Mexican stock market (bolsa), over the period of 1/4/1988 to 2/25/2004. We compute daily returns as changes in logarithms of the IPC. Although changes in stock price index do not include daily dividend yields, we do not expect this omission to alter the results of our analysis. Mills and Coutts (1995) review the literature regarding dividends and conclude that any bias in the results due to dividend exclusion will be minimal. Draper and Paudyal (1997) also support this conclusion. We base our calculations on 250 trading days per year (assuming 10 holidays per year). In section IV, when we discuss trading strategies, we use the 1-day CETES rate as the money market rate needed to estimate returns of various strategies. In order to get the approximate daily overnight rates, we divide the daily one-year CETES rate by 365 . (We could have divided by 260 , or 52 weeks with 5 working days each; however, that would overestimate the returns of various strategies that we will discuss in section IV).

Technical analysis is based on the idea that prices move in trends, which are determined by the changing attitudes of traders towards various economic, political and psychological forces. As Pring (1991, p. 2) points out "the art of technical analysis is to identify trend changes at an early stage and to maintain an investment posture until the weight of evidence indicates that the trend has reversed." One of the most important trend-determining techniques is based on the crossing of two moving averages $(M A)$ of prices. According to this rule, buy (sell) signals are emitted when the short-term moving average exceeds (is less than) the long-term moving average by a specified percentage. In this study we use long moving averages of 50,100, 150 and 200. As for the short moving average, as in the BLL study, we use 1 day (the raw price) moving average. (We have also used 5 days MA and the results were not significantly different from 1 day). Thus, a buy signal is emitted when the short moving average breaks the long one from below, and a sell signal is emitted when the short moving average breaks the long from above.

We define $P_{t}$ as the short moving average or the raw index level at time $\mathrm{t}$, and define long moving average of $\mathrm{M}$ at time $\mathrm{t}$ as:

$M A_{t}(M)=\frac{1}{M} \sum_{i=0}^{M-1} P_{t-i}$

We will test three moving average rules; the standard moving average rule (SMA), the increasing moving average rule (IMA), and the Arnold and Rahfeldt (1986) moving average rule, (ARMA). As for trading the index, we will be either in the market (buy days) or out of the market (sell days). We assume that a trader following these MA strategies could presumably observe the prices a few minutes prior to the day's close and make the trading decision at the close. If the closing price is above the long moving average (or above 1.01 times long run moving average, $1 \%$ band), then the trader will be in the market next day by buying the index at the closing price (next day will be a buy day). Next day's return will be the difference between the logarithm of the closing price next day and the logarithm of closing price the previous day. On the other hand, if the closing price is below the long moving average (or below .99 times long moving average, $1 \%$ band), then we will sell the index at the closing price and will be out of the market next day (sell days). For the increasing MA rule, the buy days are the same as standard MA rule plus the requirement that the long run MA should be increasing (positive slope). The ARMA trading rules compare the price level with two moving averages: moving average short and long. If the price index is above both moving average short and moving average long, the rule emits a buy signal and we will be in the market (buy days); we will be out of the market (sell days) if the price is below either moving average. We define mean buy and mean sell returns as follows:

$$
\begin{aligned}
& X(b)=\frac{1}{N_{b}} \sum R_{b} \\
& X(s)=\frac{1}{N_{s}} \sum R_{s}
\end{aligned}
$$


where, $N_{b}$ and $N_{s}$ are the total number of buy and sell days and $R_{b}$ and $R_{s}$ are daily returns of buy and sell days. We will test whether the returns of any moving average trading rules are greater than a buy and hold strategy and whether the mean buy is different from the mean sell. The null and alternative hypotheses are expressed as:

$$
\begin{aligned}
& H_{0}: X(b)-X(h)=0, X(s)-X(h)=0, X(b)-X(s)=0 \\
& H_{A}: X(b)-X(h) \neq 0, X(s)-X(h) \neq 0, X(b)-X(s) \neq 0
\end{aligned}
$$

where $\mathrm{X}(\mathrm{h})$ is the mean return for the buy-and-hold strategy:

$X(h)=\frac{1}{N} \sum \mathrm{R}$.

The test statistic for the mean buy returns over the mean buy-and hold strategy is

$\mathrm{t}=\frac{X(b)-X(h)}{\sqrt{\operatorname{Var}(b) / N_{b}+\operatorname{Var}(h) / N}}$

where $\operatorname{Var}(b)$ and $\operatorname{Var}(h)$ are the variance of buy and buy-and-hold returns respectively. The above formula is also used to test the mean sell returns over the mean buy-and-hold strategy; and the mean buy returns over the mean sell returns by replacing the appropriate variables in the t-statistic formula. Consistent with many other authors including BLL, all our analysis of statistical significance is performed at the level of daily returns. When necessary, we apply the following formula to calculate the annual buy and hold return:

$\mathrm{B} \& \mathrm{H}$ Ret $=\operatorname{Exp}(\mathrm{N} * \mathrm{R})-1$

where $\mathrm{N}$ is the number of days that the investment is kept (we assume 250 for annual returns) and $\mathrm{R}$ is the daily average return. This formula helps us illustrate economic significance of compounding daily returns and can also be applied to differences in return between investment strategies in order to show the economic advantage of one strategy over the other. We report that as part of our analysis we repeated our tests calculating daily returns as the percentage difference of the index (instead of using the change of logarithms in the index). Results produced essentially the same overall results as using the continuous return method and are therefore omitted.

\section{Empirical Results}

For the entire period the daily average of buy-and-hold strategy is 0.00097 ( 0.097 percent) with a standard deviation of 0.01630 . The $t$-value for the buy and hold strategy for the entire period (4163 observations) is equal to $3.83(0.0097$ divided by $0.01630 / \sqrt{4163})$. The annual average calculated using formula (6) is $27.4 \%$ for the entire period. All calculations are done in local currency. In this paper, we compare all t-statistics with 1.96, the critical tvalue at 5 percent level for large numbers of observations. The unconditional mean for the entire period is significantly different from zero; implying positive average daily returns.

Table I summarizes the results of standard moving average trading rules. Most of these trading rules were used in the BLL study. The rules are described as (1, long, percentage). For each rule we report mean returns on buy days and sell days, standard deviations of returns on buy and sell days, and total number of buy and sell days. The numbers in the parentheses are the t-statistics (equation 5) testing the difference of the mean buy and mean sell from the unconditional 1-day mean, and buy-sell from zero. 
Table I

\section{Statistical Results for Standard Moving Average Rules}

\begin{tabular}{|c|c|c|c|c|c|c|c|}
\hline \multicolumn{8}{|c|}{$\begin{array}{l}\text { Results for daily data from 4/1/88-2/25/04. Rules are identified as (short, long, band) where short and long are the } \\
\text { short and long moving averages and band is percentage difference to generate a signal. } \mathrm{N}_{\mathrm{b}} \text { and } \mathrm{N}_{\mathrm{s}} \text { are the number of } \\
\text { buy and sell signals reported in each period. } \mathrm{SD}_{\mathrm{b}} \text { and } \mathrm{SD}_{\mathrm{s}} \text { are standard deviation of buy and sell signals, respectively. } \\
\text { The numbers in the parentheses are the t-statistics testing the difference of the mean buy and mean sell from the } \\
\text { unconditional 1-day mean, and buy-sell from zero. Numbers marked with asterisks are significant at the } 5 \% \text { level for } \\
\text { a two-tailed test. }\end{array}$} \\
\hline Rules & Buy & Sell & Buy-Sell & $\mathbf{S D}_{\mathrm{b}}$ & $\mathbf{S D}_{\mathrm{s}}$ & $\mathbf{N}_{\mathbf{b}}$ & $\mathbf{N}_{\mathrm{s}}$ \\
\hline$(\mathbf{1 , 5 0 , 0 )}$ & $\begin{array}{c}0.00161 \\
(1.75)\end{array}$ & $\begin{array}{l}-0.00020 \\
(-2.01)^{*}\end{array}$ & $\begin{array}{l}0.00181 \\
(3.08)^{*}\end{array}$ & 0.01367 & 0.02019 & 2691 & 1472 \\
\hline$(1,100,0)$ & $\begin{array}{c}0.00137 \\
(1.07) \\
\end{array}$ & $\begin{array}{c}0.00014 \\
(-1.36) \\
\end{array}$ & $\begin{array}{l}0.00123 \\
(1.96)^{*}\end{array}$ & 0.01373 & 0.02048 & 2830 & 1283 \\
\hline$(1,150,0)$ & $\begin{array}{c}0.00112 \\
(0.41)\end{array}$ & $\begin{array}{c}0.00063 \\
(-0.54) \\
\end{array}$ & $\begin{array}{c}0.00049 \\
(0.77) \\
\end{array}$ & 0.01393 & 0.02033 & 2833 & 1230 \\
\hline$(1,200,0)$ & $\begin{array}{c}0.00111 \\
(0.33)\end{array}$ & $\begin{array}{c}0.00067 \\
(-0.47)\end{array}$ & $\begin{array}{c}0.00044 \\
(0.65)\end{array}$ & 0.01416 & 0.02070 & 2929 & 1084 \\
\hline $\begin{array}{c}\text { Average } \\
(1, \text { Long MA, 0) } \\
\end{array}$ & 0.00130 & 0.00031 & 0.00099 & $\mathbf{0 . 0 1 3 8 7}$ & 0.02043 & 2821 & 1267 \\
\hline \multicolumn{8}{|c|}{ Trading rules with one percent band } \\
\hline$(1,50,1)$ & $\begin{array}{l}0.00140 \\
(2.91)^{*}\end{array}$ & $\begin{array}{l}0.00017 \\
(-2.84)^{*}\end{array}$ & $\begin{array}{c}0.00123 \\
(4.7)^{*}\end{array}$ & 0.01380 & 0.02081 & 2696 & 1467 \\
\hline$(1,100,1)$ & $\begin{array}{c}0.00129 \\
(0.84)\end{array}$ & $\begin{array}{c}0.00032 \\
(-1.07)\end{array}$ & $\begin{array}{c}0.00097 \\
(1.55)\end{array}$ & 0.01371 & 0.02051 & 2828 & 1285 \\
\hline$(1,150,1)$ & $\begin{array}{c}0.00106 \\
(0.24)\end{array}$ & $\begin{array}{c}0.00078 \\
(0-.31)\end{array}$ & $\begin{array}{c}0.00028 \\
(0.45)\end{array}$ & 0.01394 & 0.02025 & 2816 & 1247 \\
\hline$(1,200,1)$ & $\begin{array}{c}0.00104 \\
(0.15) \\
\end{array}$ & $\begin{array}{c}0.00084 \\
(-0.22)\end{array}$ & $\begin{array}{c}0.00133 \\
(0.30) \\
\end{array}$ & 0.01429 & 0.02047 & 2936 & 1077 \\
\hline $\begin{array}{c}\text { Average } \\
(1, \text { Long MA, 1) }\end{array}$ & 0.00120 & 0.00053 & 0.00067 & 0.01394 & 0.02033 & 2819 & 1269 \\
\hline
\end{tabular}

The first row of Panel A reports results of trading rule $(1,50,0)$; we will be in the market (buy days) if the MA1 (Index level) is greater than MA50 and out of the market (sell days) if MA1 is less than or equal to MA50. The next to last row shows the results of trading rule $(1,200,1)$; we will be in the market (buy days) if MA1 is greater than 1.01*MA200, and will be in the market as long as the index level is above .99 times MA200 and will be out of the market (sell days) if the index level is below .99* MA200 and will be out of the market as long as the index level is below 1.01*MA200. The results of trading rules for SMA of Table I are not spectacular. Only for MA50 the buysell differences (column 4) are positive with highly significant t-stats, rejecting the null hypothesis of equality with zero. The mean buy and sell returns are shown in columns 2 and 3. Again, only the MA50 rules seem to work for trading rules. One of the eight tests rejects the null hypothesis that the buy returns equal the unconditional 1-day return. For the sells, two of the eight tests reject equality with the unconditional mean return. The standard deviations of buy days and sell days are reported in Columns 5 and 6 . The standard deviations for buy days are always smaller than those for sell days. This implies that the market is less volatile for buy periods than sell periods. Columns 7 and 8 report the number of buys and sells for various rules. On average, $69 \%$ of the time we are in the market (buy days) and $31 \%$ out of the market (sell days). We also tested all 8 rules by replacing short moving average of one day (the index level) with short moving average of 5 days, the results (not reported) were similar to MA1.

Table II presents the results of IMA and ARMA trading rules. The trading rule for IMA is as follows:

- If $\mathrm{P}>\mathrm{MA}$ (long) and if MA(long) is upsloping, then we are in the market (buy days).

- $\quad$ If $\mathrm{P} \leq \mathrm{MA}$ (long) or if MA(long) is downsloping, then we are out of the market (sell days). 
The ARMA technical trading rules advocated by Arnold and Rahfeldt, (1986, p. 71) are explained as follows: "Buy when the actual price crosses above both moving averages and exit the market when the price crosses below either market moving average." The ARMA trading rules compare the price level with two moving averages: moving average short and long. If the price index is above both moving average short and moving average long, the rule emits a buy signal and we will be in the market (buy days); we will be out of the market (sell days) if the price is below either moving average. Therefore the AR rules can be summarized as follows:

- $\quad$ If $\mathrm{P}>\mathrm{MA}$ (short) and MA(Long) we will be in the market (buy days)

- $\quad$ If $\mathrm{P} \leq$ either MA(short) or MA(long), we will be out of the market (sell days)

We will consider the ARMA trading rules for short moving average of 5 and 10 days and long moving average of 50,100,150 and 200 days. The results for short moving average of 10 days are not much different than the short moving average of 5 days, therefore are not shown. For example the first row of Panel A reports results of trading rule for IMA $(1,50,0)$; we will be in the market (buy days) if the Index level is greater than MA50 and MA50 is increasing (positive slope) and out of the market (sell days) if the price level is less than MA50 or MA50 is decreasing (negative slope). The first row of Panel B reports results of trading rule of $\mathrm{P}>(5,50)$; we will be in the market (buy days) if the price level is greater than both short moving average of 5 days and long moving average of 50 days and out of the market (sell days) if the price level is less than either moving average.

The results of panel B are stronger than the results in panel A. In panel B, the t-values for all buy and all sell are highly significant, rejecting the null hypothesis that the buy and sell returns equal the unconditional 1-day return. All the buy-sell differences are positive and the t-stats for these differences are highly significant, rejecting the null hypothesis of equality with zero. For the ARMA rules, on the average, $43 \%$ of the time we are in the market (buy days) and $57 \%$ of the time out of the market (sell days). For the IMA trading rules, the results are not as strong as ARMA rules. Two out of four buy-sell differences are positive, and the t-stats for these differences are highly significant, rejecting the null hypothesis of equality with zero. The t-values of two (out of four) sell days are highly significant, rejecting the null hypothesis that the sell returns equal the unconditional 1-day return. As for the buy days, only the t-value of $\operatorname{IMA}(1,50,0)$ is highly significant, rejecting the null hypothesis that the buy returns equal the unconditional 1-day return. For the IMA rules, on the average, $63 \%$ of the time we are in the market (buy days) and $37 \%$ of the time out of the market (sell days).

The negative returns in Table II for sell days are especially noteworthy. As BLL points out, these returns cannot be explained by seasonality since they are based on 37\% (IMA) and 57\% (ARMA) of all trading days. This predictability of returns can reflect either (1) changes in expected returns generated from an equilibrium model, or (2) market inefficiency. Although changes in expected returns are possible, it is hard to imagine an equilibrium model that predicts negative returns over such a large fraction of trading days.

If technical analysis did not have any power to forecast price movements, then we should observe that the buy days returns do not differ appreciably from sell days returns. However, the results of Table II indicate that moving average rules do indeed have predictive power and can discern recurring-price patterns for profitable trading. Given this predictive power of technical analysis, can we design various trading strategies to beat the buyand-hold strategy? 
Table II

Statistical Results for Increasing and Arnold and Rahfeldt Moving Average Rules

\begin{tabular}{|c|c|c|c|c|c|c|c|}
\hline \multirow{2}{*}{\multicolumn{8}{|c|}{$\begin{array}{l}\text { Results for daily data from } 4 / 1 / 88 \text { to } 2 / 25 / 2004 \text {. Rules are identified as IMA(1, long } \\
\text { means: buy if the index level is greater than moving average of } 50 \text { days and if movin } \\
\text { index level is less than moving average } 50 \text { or MA50 is decreasing. } \mathrm{N}_{\mathrm{b}} \text { and } \mathrm{N}_{\mathrm{s}} \text { are the } \\
\text { in each period. } \mathrm{SD}_{\mathrm{b}} \text { and } \mathrm{SD}_{\mathrm{s}} \text { are standard deviations of buy and sell signals, respective } \\
\text { the t-statistics testing the difference of the mean buy and mean sell from the uncond } \\
\text { zero. Numbers marked with asterisks are significant at the } 5 \% \text { level for a two-tailed test } \\
\text { Panel A: Increasing Moving Average Rules }\end{array}$}} \\
\hline & & & & & & & \\
\hline Rules & Buy & Sell & Buy-Sell & $\mathbf{S D}_{\mathrm{b}}$ & $\mathbf{S D}_{\mathrm{s}}$ & $\mathbf{N}_{b}$ & $\mathbf{N}_{\mathrm{s}}$ \\
\hline $\operatorname{IMA}(1,50,0)$ & $\begin{array}{l}0.00206 \\
(2.93)^{*}\end{array}$ & $\begin{array}{c}-0.00052 \\
(-2.83)^{*}\end{array}$ & $\begin{array}{l}0.00258 \\
(4.81)^{*}\end{array}$ & 0.01352 & 0.01935 & 2396 & 1767 \\
\hline IMA $(1,100,0)$ & $\begin{array}{c}0.00169 \\
(1.89)\end{array}$ & $\begin{array}{l}-0.00017 \\
(-2.08)^{*}\end{array}$ & $\begin{array}{l}0.00186 \\
(3.28)^{*}\end{array}$ & 0.01364 & 0.01958 & 2569 & 1544 \\
\hline $\operatorname{IMA}(1,150,0)$ & $\begin{array}{c}0.00132 \\
(0.92) \\
\end{array}$ & $\begin{array}{c}-0.00040 \\
(-1.05)\end{array}$ & $\begin{array}{c}0.00172 \\
(1.65)\end{array}$ & 0.01405 & 0.01912 & 2541 & 1522 \\
\hline IMA $(1,200,0)$ & $\begin{array}{c}0.00123 \\
(0.65)\end{array}$ & $\begin{array}{c}-0.00048 \\
(-0.84)\end{array}$ & $\begin{array}{c}0.00075 \\
(1.23)\end{array}$ & 0.01419 & 0.01972 & 2718 & 1295 \\
\hline Average & 0.00158 & -0.00005 & 0.00173 & 0.01385 & 0.01944 & 2556 & 1532 \\
\hline \multicolumn{8}{|c|}{ Panel B: Arnold and Rahfeldt Moving Average Rules } \\
\hline P>MA(5,50) & $\begin{array}{l}0.00276 \\
(4.51)^{*}\end{array}$ & $\begin{array}{c}-0.00037 \\
(-2.96)^{*}\end{array}$ & $\begin{array}{c}0.00313 \\
(6.46)^{*}\end{array}$ & 0.01292 & 0.01831 & 1782 & 2381 \\
\hline $\mathbf{P}>\mathrm{MA}(\mathbf{5 , 1 0 0})$ & $\begin{array}{l}0.00277 \\
(4.54)^{*}\end{array}$ & $\begin{array}{l}-.00036 \\
(-2.97)^{*}\end{array}$ & $\begin{array}{l}0.00312 \\
(6.48)^{*}\end{array}$ & 0.01264 & 0.01825 & 1771 & 2342 \\
\hline $\mathbf{P}>\mathrm{MA}(\mathbf{5 , 1 5 0 )}$ & $\begin{array}{l}0.00268 \\
(4.32)^{*}\end{array}$ & $\begin{array}{l}-0.00030 \\
(-2.80)^{*}\end{array}$ & $\begin{array}{l}0.00298 \\
(6.15)^{*}\end{array}$ & 0.01264 & 0.01822 & 1736 & 2327 \\
\hline $\mathbf{P}>\mathrm{MA}(\mathbf{5 , 2 0 0 )}$ & $\begin{array}{l}0.00279 \\
(4.52)^{*}\end{array}$ & $\begin{array}{l}-0.00042 \\
(-3.06)^{*}\end{array}$ & $\begin{array}{l}0.00321 \\
(6.54)^{*}\end{array}$ & 0.01285 & 0.01826 & 1765 & 2248 \\
\hline Average & 0.00275 & -0.00036 & 0.00311 & 0.01276 & 0.01826 & 1764 & 2325 \\
\hline
\end{tabular}

\section{Trading Strategies}

We next provide some information on the degree to which traders using these technical trading rules can earn trading profits that could beat the buy-and-hold strategy. Given that the mean buy is greater than the mean sell and the unconditional 1-day mean, the profitability of technical trading rules depends on trading strategy, especially, what position the trader should take when the rule emits sell signals. If the trader does not invest on the sell days, then the trader's return on the sell days will be zero which will result in a mean return of $\left(N_{b} / N\right) * X(b)+\left(N_{s} / N\right) * 0$ for this strategy. In this study we consider two strategies: (1) the trader will be in the stock market when trading rules emit buy signals and be in the money market when it emits sell signals (long/money) and (2) the trader will borrow at the money market rate (CETES) to double stock investment when trading rules emit buy signals and be in the money market when it emits sell signals (leverage/money). The total trading return on buy days of this strategy is $T R_{t}=2 * R_{t}-M_{t}$, where $R_{\mathrm{t}}$ is the index return on day $\mathrm{t}$ and $M_{t}$ is the daily CETES return on day $\mathrm{t}$.

For each strategy we estimate the daily return and then subtract from it the daily return from buy-and-hold strategy to get the daily difference return. To test whether the average daily difference is greater than zero, we express the null and alternative hypotheses as follows:

$\mathrm{H}_{0}:$ ddif $\leq 0$

$\mathrm{H}_{\mathrm{A}}:$ ddif $>0$ 
The t-statistic for the above test is:

$\mathbf{t}=\frac{X(\text { ddif })}{\sqrt{\operatorname{Var}(\text { ddif }) / N}}$

where $X($ ddif $)$ is the average daily difference of returns of each strategy over the buy-and-hold strategy, $\operatorname{Var}($ ddif) is the variance of daily difference returns, and $\mathrm{N}$ is the total number of days. Table III reports the results of the above two strategies for IMA and ARMA rules.

Table III

Statistical Results for Trading Strategies

\begin{tabular}{|c|c|c|c|c|}
\hline $\begin{array}{l}X(\text { ddif }) \text { and } S D(\text { ddif }) \\
\text { and-hold strategy. T } \\
\text { zero. Numbers mark }\end{array}$ & $\begin{array}{l}\text { and stan } \\
\text { in the pa } \\
\text { isks are } \mathrm{s}\end{array}$ & $\begin{array}{l}\text { f daily di } \\
\text { le t-statis } \\
5 \% \text { level }\end{array}$ & $\begin{array}{l}\text { n the retu } \\
\text { equality o } \\
\text { test. }\end{array}$ & $\begin{array}{l}\text { egy and } t \\
\text { differenc }\end{array}$ \\
\hline & & ing Movi & & \\
\hline & & & & \\
\hline Rules & $\mathrm{X}$ (ddif) & SD(ddif) & X(ddif) & SD(ddif) \\
\hline $\operatorname{IMA}(1,50,0)$ & $\begin{array}{l}0.00049 \\
(2.51)^{*}\end{array}$ & .01261 & $\begin{array}{l}0.00130 \\
(5.18)^{*}\end{array}$ & 0.01624 \\
\hline $\operatorname{IMA}(1,100,0)$ & $\begin{array}{c}0.00029 \\
(1.56)\end{array}$ & 0.01199 & $\begin{array}{l}0.00094 \\
(3.75)^{*}\end{array}$ & 0.01611 \\
\hline IMA(1,150,0) & $\begin{array}{c}0.00007 \\
(0.37)\end{array}$ & 0.01169 & $\begin{array}{l}0.00049 \\
(1.94)^{*}\end{array}$ & 0.01612 \\
\hline $\operatorname{IMA}(1,200,0)$ & $\begin{array}{c}0.00003 \\
(0.19)\end{array}$ & 0.01119 & $\begin{array}{c}0.00044 \\
(1.73)\end{array}$ & 0.01617 \\
\hline Average IMA & 0.00022 & 0.01187 & 0.00079 & 0.01616 \\
\hline $\begin{array}{c}\text { Average annual } \\
\text { difference }\end{array}$ & 0.05670 & & 0.21986 & \\
\hline & Panel B & Rahfeldt I & e Rules & \\
\hline $\mathrm{P}>\mathrm{MA}(5,50)$ & $\begin{array}{l}0.00058 \\
(2.69)^{*}\end{array}$ & 0.01386 & $\begin{array}{c}0.00148 \\
(5.88)^{*}\end{array}$ & 0.01623 \\
\hline $\mathrm{P}>\mathrm{MA}(5,100)$ & $\begin{array}{l}0.00055 \\
(2.56)^{*}\end{array}$ & 0.01377 & $\begin{array}{l}0.00146 \\
(5.83)^{*}\end{array}$ & 0.01607 \\
\hline $\mathrm{P}>\mathrm{MA}(5,150)$ & $\begin{array}{l}0.00052 \\
(2.39)^{*}\end{array}$ & 0.01379 & $\begin{array}{l}0.00139 \\
(5.51)^{*}\end{array}$ & 0.01607 \\
\hline $\mathrm{P}>\mathrm{MA}(5,200)$ & $\begin{array}{l}0.00058 \\
(2.67)^{*}\end{array}$ & 0.01377 & $\begin{array}{l}0.00153 \\
(6.01)^{*}\end{array}$ & 0.01610 \\
\hline Average ARMA & 0.00058 & 0.01377 & 0.00146 & 0.01612 \\
\hline $\begin{array}{c}\text { Average annual } \\
\text { difference }\end{array}$ & 0.14892 & & 0.44208 & \\
\hline
\end{tabular}

As shown in Table III, both IMA and ARMA rules for the second strategy (leverage/money) beat the buyand-hold strategy; and in 7 out of 8 cases reject the null hypothesis that the average daily difference is less than or equal to zero. The average standard deviations of the second strategy ( 0.01616 for IMA and 0.01612 for ARMA) are similar to the standard deviation of buy and hold strategy (0.01630). Therefore, strategy two has higher average returns but not higher risks; they beat the market as implied by their high and significant t-values. As for strategy one (long/money) The ARMA rules beat the buy-and-hold strategy again. The t-values are all significant, rejecting the null hypothesis that the average daily difference is less than or equal to zero. However, only IMA50 for strategy one beats the buy-and-hold strategy; for IMA rules, the MA 100, 150, 200 are not working. When we use formula 
(6) to evaluate the economic significance of the return differences we see that on an annual basis, strategy 2 based on IMA outperforms buy and hold by $22 \%$ and strategy 2 based on ARMA exceeds buy and hold by $44.2 \%$.

Advocates of the weak-form market efficiency hypothesize that investors could not drive profits above a buy-and-hold policy using any trading rule that depends only on past market information such as price. The results of Table III cast doubt on weak-form market efficiency and support the notion that moving average trading rules contains substantial information to predict changes in the IPC.

In conclusion, we have identified a strategy (strategy 2, leverage/money) that is based on technical trading that significantly beats the buy-and-hold strategy. Although the discovery of profitable trading rules may be helpful in understanding market dynamics, traders may not be able to exploit these rules without considering transaction costs. In order to account for the transaction costs of strategy 2, we report in Table IV, the "break-even" transaction costs, which are the one-way percentage cost that eliminates the additional return from technical trading. We also report annual transaction costs assuming that one-way transaction cost is $0.5 \%$.

The first column of Table IV identifies trading rules; the second column is the average daily difference returns between the strategy 2 (leverage/money) and the buy-and-hold strategy. In column 3, we obtain the annualized excess returns using formula 6. Column 4 reports total trades, numbers of in and out of the market signals, or total frequency of transactions, implied by a specific trading rule. In column 5 , we report average trades per year; or total trades divided by 16, the number of years under consideration. Column 6 reports one-way "breakeven" transaction cost; or annual excess return divided by average number of trades per year. One-way transaction cost is assumed to be the same for buying and selling the index. Finally, in the last column we estimate annual transaction costs assuming that one-way transaction cost is $0.5 \%$. Given that Knez and Ready (1996) have estimated one-way transaction cost for DJIA index to be $0.26 \%$, that Bessembinder and Chan (1995) estimate a one-way equity trading cost of $0.24 \%$ to $0.26 \%$ for institutional traders, and that Wells Fargo Nikko Investment Advisors estimates its own one-way trading costs to be $0.25 \%$ (Kroner 1995), our choice of $0.5 \%$ one-way transaction cost seems to be very conservative and realistic.

The break-even one-way trading costs in column 6 , which would just eliminate excess returns of strategy 2 , are between $1.06 \%$ and $3.20 \%$ for various rules. One-way breakeven costs for increasing MA rules are higher than ARMA rules. This is because the ARMA rules produce many signals and therefore many transactions. We believe that these break-even one-way trading costs are large compared to recent estimates of actual trading costs, especially for the IMA rules. If a trader's one-way transaction cost is below the break-even transaction costs of Table IV, the trader can use IMA or ARMA rules and adopt strategy 2 (leverage/long) and beat the buy-and-hold strategy even considering transaction costs. The extra profits over the buy-and-hold strategy will be higher for increasing MA rules. The last column of Table IV also reports average annual costs of trading in and out of the market assuming a one-way trading cost of $0.5 \%$; these annual trading costs are much lower than the excess return from using trading rules (as shown in column 3), implying profitable technical trading for IPC even when considering transaction costs. In summary, our results provide support for technical trading rules that can be exploited.

\section{Robustness Test}

We provide a robustness test for the trading rules that we previously examine in order to avoid the possible data-snooping problem. The robustness test is to evaluate whether the benchmark strategy, which is buy-and-hold strategy in this research, underperforms the selected technical trading rules. Sullivan, Timmermann, and White (1999) analyze the data-snooping problem that arises in technical trading rules by using White's Reality Check (RC) proposed by White (2000). RC is to verify if the trading rules that we select are superior to the benchmark model. However, the puzzle is that we first need to construct a universe of trading rules before doing the comparison. According to Hansen (2005), the success of RC centers on the requirement that it needs to include the full collection of technical trading rules. Also, RC is very sensitive to the inclusion of inappropriate and weak alternatives. 
Table IV

Break-Even Trading Costs for Strategy Based on Leverage

\begin{tabular}{|c|c|c|c|c|c|c|}
\hline \multirow{2}{*}{\multicolumn{7}{|c|}{$\begin{array}{l}\mathrm{X}(\mathrm{ddif}) \text { is average daily difference between the return of strategy } 2 \text { (leverage/mone } \\
\text { table IV. Annual Excess return is EXP(X(ddif) times } 250)-1 \text {. Total trades represent th } \\
\text { from in and out of the market. Trade per year is total trades divided by number of ye } \\
\text { the ratio of annual excess return over trades per year. Annual costs are estimated assum } \\
\text { Panel A: Increasing Moving Average Rules }\end{array}$}} \\
\hline & & & & & & \\
\hline Rules & $\begin{array}{c}\text { Strategy } 2 \\
\text { X(ddif) }\end{array}$ & $\begin{array}{c}\text { Annual Excess } \\
\text { Return } \%\end{array}$ & $\begin{array}{l}\text { Total } \\
\text { Trades }\end{array}$ & $\begin{array}{c}\text { Trades } \\
\text { Per year }\end{array}$ & $\begin{array}{c}\text { One way } \\
\text { Break-even } \\
\text { Costs \% }\end{array}$ & $\begin{array}{c}\text { Estimated } \\
\text { annual } \\
\text { transaction } \\
\text { costs }(\%)\end{array}$ \\
\hline IMA $(1,50,0)$ & 0.00130 & $38.56 \%$ & 193 & 12.1 & $3.20 \%$ & $6.0 \%$ \\
\hline IMA $(1,100,0)$ & 0.00094 & $26.58 \%$ & 143 & 8.9 & $2.97 \%$ & $4.5 \%$ \\
\hline $\operatorname{IMA}(1,150,0)$ & 0.00049 & $13.03 \%$ & 103 & 6.4 & $2.02 \%$ & $3.2 \%$ \\
\hline $\operatorname{IMA}(1,200,0)$ & 0.00044 & $11.70 \%$ & 121 & 7.6 & $1.55 \%$ & $3.8 \%$ \\
\hline Average & 0.00079 & $22.47 \%$ & 140 & 8.8 & $2.44 \%$ & $4.4 \%$ \\
\hline \multicolumn{7}{|c|}{ Panel B: Arnold and Rahfeldt Moving Average Rules } \\
\hline $\mathrm{P}>\mathrm{MA}(5,50)$ & 0.00148 & $44.71 \%$ & 655 & 40.9 & $1.09 \%$ & $20.5 \%$ \\
\hline $\mathrm{P}>\mathrm{MA}(5,100)$ & 0.00146 & $44.10 \%$ & 644 & 40.3 & $1.10 \%$ & $20.1 \%$ \\
\hline $\mathrm{P}>\mathrm{MA}(5,150)$ & 0.00139 & $41.55 \%$ & 630 & 39.4 & $1.06 \%$ & $19.7 \%$ \\
\hline $\mathrm{P}>\mathrm{MA}(5,200)$ & 0.00153 & $46.52 \%$ & 644 & 40.3 & $1.16 \%$ & $20.1 \%$ \\
\hline Average & 0.00146 & $44.22 \%$ & 643 & 40.2 & $1.10 \%$ & $20.1 \%$ \\
\hline
\end{tabular}

Hansen (2005) initiates a new test statistic named Superior Predictive Ability (SPA) that is an improvement over RC. SPA does not rely on the construction of a universe of trading rules. Instead, SPA uses a studentized test statistic and dependent null distribution so that it avoids the problem caused by the enclosure of poor alternatives. Furthermore, SPA weighs the selected trading rules against the benchmark in terms of expected loss. The null hypothesis is that the buy-and-hold strategy is superior to all the technical trading rules. The mathematical presentation of the methodology is offered and explained as follows. We define

$S_{i, t}=k\left(r_{t}, d_{0, t-h}\right)-k\left(r_{t}, d_{i, t-h}\right), \mathrm{i}=1, \ldots, \mathrm{n}$

where $S_{i, t}$ stands for the difference of performance between trading rule $i$ and the benchmark at time $t$. $k$ denotes the loss function with $\mathrm{r}$ representing the random variable based on the decision rules $\mathrm{d}$. $\mathrm{d}_{0, \mathrm{t} \text {, }}$ denotes the benchmark model, and $\mathrm{d}_{\mathrm{i}, \mathrm{th}}$ is the trading rule. The expected difference of performance is $\phi=E\left(S_{t}^{v}\right)$, where v denotes vector. Moreover, the null hypothesis and the studentized test statistics are shown as

$H_{0}: \phi \leq 0$
$t^{S P A}=\max \left[\max _{i=1, \ldots, n} \frac{\sqrt{m} \overline{S_{i}}}{\hat{\sigma}}, 0\right]$

where $\mathrm{m}$ is the number of observations, $\bar{S}$ stands for the mean of the $\mathrm{S}$ vectors, and $\hat{\sigma}$ is the estimator of the standard deviation of the $\mathrm{S}$ vectors. To estimate the loss function, we employ bootstrap methodology by which the number of resamples and the bootstrap parameter are adjusted at the appropriate levels. Also adopted for the loss function is the mean squared error (MSE), which is one of most commonly used techniques for the loss function.

The result of robustness tests is presented in Table $\mathrm{V}$ that shows four alternative SPA models with different bootstrap parameters by using the loss function of mean squared error. Notably, the most significant model among the 32 trading rules is S1IMA $(1,150)$ or strategy one of increasing moving average 1 and 50 , across all models. The last column of the Table V shows the SPA p-value which is the indication of significance for the entire pool of 
trading rules that we examine against the benchmark strategy. We can see that all SPA p-values are quite significant across the models tested by different bootstrap parameters, rejecting the hypothesis that the benchmark trading strategy is not inferior to our selected trading strategies in view of data-snooping problem.

Table V

Robustness Test by SPA

\begin{tabular}{|c|c|c|c|c|}
\hline \multicolumn{5}{|c|}{$\begin{array}{l}\text { This table shows the robustness test by Superior Predictive Ability proposed by Hansen (2005). Where "*" represents } 50 \\
\text { significance and the bootstrap parameters B is the number of resampling and q denotes dependence. The sample loss } \\
\text { computed by the loss function of mean squared error, MSE. The most significant model among the } 32 \text { trading rules } \\
\text { reported along with the sample loss and p-value. The last column of the table shows the SPA p-value which is the indicatio } \\
\text { of significance for the entire pool of trading rules that we examine against the benchmark strategy. The null hypothesis is tha } \\
\text { the benchmark trading strategy is not inferior to the selected trading strategies in view of data snooping problem. }\end{array}$} \\
\hline \multirow[t]{2}{*}{ Bootstrap parameters** } & \multicolumn{3}{|c|}{ Most Significant Model } & \multirow[t]{2}{*}{ SPA p-value } \\
\hline & Model & Sample Loss & p-value & \\
\hline $\mathrm{B}=1000, \mathrm{q}=0.5$ & S1IMA $(1,150)$ & 0.00013 & $0.000 *$ & $0.002 *$ \\
\hline $\mathrm{B}=1000, \mathrm{q}=0.25$ & S1IMA(1,150) & 0.00013 & $0.001 *$ & $0.001 *$ \\
\hline $\mathrm{B}=10000, \mathrm{q}=0.5$ & S1IMA $(1,150)$ & 0.00013 & $0.0001^{*}$ & $0.0004 *$ \\
\hline $\mathrm{B}=10000, \mathrm{q}=0.25$ & S1IMA $(1,150)$ & 0.00013 & $0.0005^{*}$ & $0.001 *$ \\
\hline
\end{tabular}

Another way of testing for the robustness of our results is to divide the period under consideration into two sub-periods and apply the moving average rules to each sub-period. We apply various MA rules to sub-periods $1 / 4 / 1988$ to $12 / 31 / 1995$ and $1 / 2 / 1996$ to $2 / 25 / 2004$. Table VI presents the results for various moving average rules for each sub-period.

Table VI

Statistical Results of the Moving Average Rules for Two Sub-periods

\begin{tabular}{|c|c|c|c|c|c|c|c|}
\hline \multirow{2}{*}{\multicolumn{8}{|c|}{$\begin{array}{l}\text { Results for daily data for each sub-period. Rules are identified as Standard Moving Average(SMA), Increasing Moving } \\
\text { Average (IMA) and Arnold and Rahfeldt Moving Average Rules (P>(MA }(5,50)) \text {. Nb and Ns are the number of buy and sell } \\
\text { signals reported in each period. SDb and SDs are standard deviations of buy and sell signals, respectively. The numbers in } \\
\text { the parentheses are the t-statistics testing the difference of the mean buy and mean sell from the unconditional 1-day mean, } \\
\text { and buy-sell from zero. Numbers marked with asterisks are significant at the 5\% level for a two-tailed test. } \\
\text { Panel A: Period 1988- 1995 }\end{array}$}} \\
\hline & & & & & & & \\
\hline Rules & Buy & Sell & Buy-Sell & $\mathbf{S D}_{\mathbf{b}}$ & $\mathbf{S D}_{\mathrm{s}}$ & $\mathbf{N}_{\mathrm{b}}$ & $\mathbf{N}_{\mathrm{s}}$ \\
\hline SMA $(1,50,0)$ & $\begin{array}{c}0.00222 \\
(1.69) \\
\end{array}$ & $\begin{array}{l}-0.00046 \\
(-2.14)^{*} \\
\end{array}$ & $\begin{array}{l}0.00268 \\
(3.14)^{*} \\
\end{array}$ & 0.01383 & 0.01977 & 1376 & 659 \\
\hline $\operatorname{IMA}(1,50,0)$ & $\begin{array}{l}0.00251 \\
(2.20)^{*}\end{array}$ & $\begin{array}{l}-0.00049 \\
(-2.40)^{*}\end{array}$ & $\begin{array}{l}0.00300 \\
(3.84)^{*}\end{array}$ & 0.01368 & 0.01908 & 1251 & 784 \\
\hline $\mathrm{P}>\mathrm{MA}(5,50)$ & $\begin{array}{c}0.00375 \\
(4.30)^{*}\end{array}$ & $\begin{array}{c}-0.00061 \\
(-3.05)^{*}\end{array}$ & $\begin{array}{c}0.00436 \\
(6.34)^{*}\end{array}$ & 0.01298 & 0.01794 & 917 & 1118 \\
\hline \multicolumn{8}{|c|}{ Panel B: Period 1996 - 2004} \\
\hline SMA $(1,50,0)$ & $\begin{array}{c}0.00096 \\
(0.71)\end{array}$ & $\begin{array}{c}0.00001 \\
(-0.73)\end{array}$ & $\begin{array}{c}0.00091 \\
(1.18)\end{array}$ & 0.01348 & 0.02054 & 1314 & 813 \\
\hline $\operatorname{IMA}(1,100,0)$ & $\begin{array}{c}0.00157 \\
(1.83)\end{array}$ & $\begin{array}{c}-0.00054 \\
(-1.58)\end{array}$ & $\begin{array}{l}0.00211 \\
(2.86)^{*}\end{array}$ & 0.01333 & 0.01957 & 1144 & 983 \\
\hline $\mathrm{P}>\mathrm{MA}(5,50)$ & $\begin{array}{c}0.00171 \\
(1.97)^{*}\end{array}$ & $\begin{array}{c}-0.00016 \\
(-1.20)\end{array}$ & $\begin{array}{c}.00187 \\
(2.74)^{*}\end{array}$ & 0.01279 & 0.01865 & 865 & 1262 \\
\hline
\end{tabular}

As can be seen from panel A in Table VI, for sub-period 1988-1995, the t-values for all buy and all sell are highly significant for increasing moving average and AR moving average rules, rejecting the null hypothesis that the buy and sell returns equal the unconditional 1-day return. All the buy-sell differences are positive and the t-stats for these differences are highly significant, rejecting the null hypothesis of equality with zero. However, for the second 
sub-period, 1996 to 2004, the results are not as strong as the first sub-period's. Even in the second sub-period for increasing moving average and AR moving average the buy-sell differences are positive and the t-stats for these differences are highly significant, rejecting the null hypothesis of equality with zero. It seems, therefore, that technical trading rules could work for increasing moving average and AR moving average rules. In Table VII we present the results of various trading strategies and break-even cost estimation for increasing moving average and AR moving average rules for each sub-period.

Table VII

Statistical Results for Trading Strategies for Each Sub-Period

\begin{tabular}{|c|c|c|c|c|c|c|}
\hline \multirow{2}{*}{\multicolumn{7}{|c|}{$\begin{array}{l}\mathrm{X}(\mathrm{ddif}) \text { and } \mathrm{SD}(\mathrm{ddif}) \text { are average and standard deviation of daily differenc } \\
\text { and-hold strategy. The numbers in the parentheses are the t-statistics tes } \\
\text { zero. Numbers marked with asterisks are significant at the 5\% level for a o } \\
\text { (IMA) and Arnold Rahfeldt Moving Average Rules }(\mathrm{P}>(\mathrm{MA}(5,50)) \text {. Pane } \\
\text { Annual costs are estimated assuming one-way transaction cost of } 0.5 \% \text {. } \\
\text { Panel A: 1988 - 1995 }\end{array}$}} \\
\hline & & & & & & \\
\hline & \multicolumn{3}{|c|}{ Strategy 1: Long/Money } & \multicolumn{3}{|c|}{ Strategy 2 : Leverage/Money } \\
\hline Rules & $\mathrm{X}$ (diff) & $\mathrm{SD}$ (diff) & $\begin{array}{c}\text { Annual } \\
\text { difference }\end{array}$ & $\mathrm{X}($ diff $)$ & $\mathrm{SD}$ (diff) & $\begin{array}{c}\text { Annual } \\
\text { difference }\end{array}$ \\
\hline $\operatorname{IMA}(1,50,0)$ & $\begin{array}{c}0.00051 \\
(1.96)^{*}\end{array}$ & 0.01184 & $13.71 \%$ & $\begin{array}{l}0.00154 \\
(4.35)^{*}\end{array}$ & 0.01596 & $46.97 \%$ \\
\hline $\mathrm{P}>\mathrm{MA}(5,50)$ & $\begin{array}{l}0.00079 \\
(2.67)^{*}\end{array}$ & 0.01331 & $21.76 \%$ & $\begin{array}{l}0.00290 \\
(5.92)^{*}\end{array}$ & 0.01590 & $68.52 \%$ \\
\hline \multicolumn{7}{|c|}{ Panel B: 1996 - 2004} \\
\hline & \multicolumn{3}{|c|}{ Strategy 1: Long/Money } & \multicolumn{3}{|c|}{ Strategy 2 : Leverage/Money } \\
\hline $\operatorname{IMA}(1,50,0)$ & $\begin{array}{c}0.00047 \\
(1.62)\end{array}$ & 0.01331 & $12.44 \%$ & $\begin{array}{l}0.00108 \\
(3.02) *\end{array}$ & 0.01650 & $31.01 \%$ \\
\hline $\mathrm{P}>\mathrm{MA}(5,50)$ & $\begin{array}{c}0.00038 \\
(1.21) \\
\end{array}$ & 0.01436 & $9.88 \%$ & $\begin{array}{c}0.00090 \\
(2.50)^{*}\end{array}$ & 0.01651 & $25.09 \%$ \\
\hline \multicolumn{7}{|c|}{ Break-Even Trading Costs for Strategy 2 Based on Leverage } \\
\hline \multicolumn{7}{|c|}{ Panel C: 1988 - 1995} \\
\hline Rules & $\begin{array}{c}\text { Strategy } 2 \\
\text { X(ddif) }\end{array}$ & $\begin{array}{c}\text { Annual Excess } \\
\text { Return \% }\end{array}$ & $\begin{array}{c}\text { Total } \\
\text { Trades }\end{array}$ & $\begin{array}{l}\text { Trades } \\
\text { Per year }\end{array}$ & $\begin{array}{c}\text { One way } \\
\text { Break-even } \\
\text { Costs \% }\end{array}$ & $\begin{array}{l}\text { Estimated } \\
\text { annual } \\
\text { transaction } \\
\text { costs }(\%)\end{array}$ \\
\hline $\operatorname{IMA}(1,50,0)$ & 0.00154 & $46.97 \%$ & 103 & 12.9 & $3.65 \%$ & $6.44 \%$ \\
\hline $\mathrm{P}>\mathrm{MA}(5,50)$ & 0.00290 & $68.52 \%$ & 293 & 36.6 & $1.87 \%$ & $18.31 \%$ \\
\hline \multicolumn{7}{|c|}{ Panel D: 1996 - 2004} \\
\hline $\operatorname{IMA}(1,50,0)$ & 0.00108 & $31.01 \%$ & 91 & 11.4 & $2.73 \%$ & $5.69 \%$ \\
\hline $\mathrm{P}>\mathrm{MA}(5,50)$ & 0.00090 & $25.09 \%$ & 363 & 45.4 & $0.55 \%$ & $22.69 \%$ \\
\hline
\end{tabular}

As shown in Table VII, panel A, for the first sub-period both IMA and ARMA rules for both strategies (Long/Money and leverage/money) beat the buy-and-hold strategy; their average t-values are highly significant, rejecting the null hypothesis that the average daily difference is less than or equal to zero. However, for the second sub-period of panel B, only the second strategy (Money/Leverage) for both moving average rules (IMA and ARMA) beat the buy-and-hold strategy; their t-values of 3.02 for IMA and 2.50 for ARMA are highly significant, rejecting the null hypothesis that the average daily difference is less than or equal to zero. Given that the second strategy (Leverage/Money) has worked well for both sub-periods, in Panel C and D of Table VII, we estimate the break-even cost of this strategy for both IMA and ARMA rules.

Panel C of Table VII shows that the one-way breakeven costs are 3.65 and 1.87 percent respectively for IMA and ARMA rules in the first sub-period. The break-even cost for ARMA rules are lower because the ARMA 
rules produce many signals and, therefore, many transactions. For the second sub-period of panel D, again the oneway breakeven costs for IMA rule $(2.72 \%)$ is higher than the break-even cost for ARMA rule $(0.55 \%)$. We believe that these break-even one-way trading costs are large compared to recent estimates of actual trading costs, especially for the IMA rules. Therefore, using increasing moving average rules in conjunction with strategy 2 (Leverage/Money) produces strong results that beat the buy-and-hold strategy for the entire period and for each subperiod.

\section{Conclusions}

Several papers have recently presented evidence that some simple trading rules are useful for predicting stock market returns. In this paper, we investigate three moving average trading rules for the IPC index in the Mexican Stock market over the period 4/1/1988 - 2/25/2004. Overall results provide strong support for the technical trading rules that we explored. If technical analysis does not have any power to forecast price movements, then we should observe that the buy days' returns do not differ appreciably from sell days' returns; our results show that most buy-sell differences are positive and the t-stats for these differences are highly significant, rejecting the null hypothesis of equality of buy days' returns with sell days' returns. Our results indicate that moving average rules do indeed have predictive power and could discern recurring-price patterns for profitable trading. Given this predictive power of technical analysis, we asked whether we could design various trading strategies to beat the buy-and-hold strategy. Our results on trading strategies support the hypothesis that technical trading rules can outperform the buyand-hold strategy. Strategy 2 (the trader will borrow at the money market rate and double stock investment when trading rules emit buy signals and be in the money market when it emits sell signals) beats the-buy-and-hold strategy over the period under consideration. Although the discovery of profitable trading rules may be helpful in understanding market dynamics, traders must also consider transaction costs. We calculated the break-even one-way trading costs for strategy 2, which significantly beats the buy-and-hold strategy over the 16-year period and in each of the two sub-periods. Our results for the breakeven cost are large compared to our estimate of actual trading costs of $0.5 \%$. We conclude that there are technical trading rules that have predictive power and may be used to design a trading strategy that will beat the buy-and-hold strategy in the Mexican stock market.

\section{Acknowledgements}

We are grateful to Jurgen Doornik and Marius Ooms for providing Ox programming language and its instruction manual for this study. We also thank Peter Reinhard Hansen at Stanford University for the assistance in using the codes of Superior Predictive Ability. All errors remain our own. For correspondence, contact the first author at metghalchim@uhv.edu or 281-275-3381.

\section{References}

1. Alexander S., Price Movements in Speculative Markets: Trends or Random Walks, Industrial Management Review, 1964, 2, pp. 25-46.

2. Arnold C.M. and Rahfeldt, D., Timing The Market: How to Profit in Bull and Bear Markets with Technical Analysis, Chicago: Probus Publishing, 1986.

3. Bessembinder H. and Chan K., Market Efficiency and Returns to Technical Analysis, Financial Management, 1998, 27, (2), pp. 5-17.

4. Bessembinder H. and Chan K., The Profitability of Technical Trading Rules in the Asian Stock Markets, Pacific-Basin Finance Journal, 1995, 3, pp. 257-284.

5. Brock W., Lakonishok, J., and LeBaron B., Simple Technical Trading Rules and the Stochastic Properties of Stock Returns, Journal of Finance, 1992, 47, pp. 1731-64.

6. Coutts A., and Cheung K.C., Trading rules and stock returns: some preliminary short run evidence from the Hang Seng 1985-1997, Applied Financial Economics, 2000, 10, pp. 579-686.

7. Draper P. and Paudyal K., Microstructure and seasonality in the UK equity market, Journal of Business Finance and Accounting, 1997, 24, pp. 1177-1204.

8. Ergul A, Holmes P., and Priestley R., Technical Analysis, Trading Volume and Market Efficiency: Evidence from an Emerging Market, Applied Financial Economics, 1997, 7, pp. 361-65. 
9. Fama E. and Blume M., Filter Rules and Stock Market Trading Profits, Journal of Business, 1966, 39, pp. 226-341.

10. Fama E., Efficient Capital Markets: A review of theory and empirical work, Journal of Finance, 1970, 25, pp.383-417.

11. Fama E., The Behavior of Stock Market Prices, Journal of Business, 1965, 38, pp. 34-105.

12. Fong W.M. and Ho Y. W., Simple Trading Rules and the Market for Internet Stocks, International Review of Finance, 2001, 2:4, pp. 247-268.

13. Gencay R., Optimization of Technical trading strategies and profitability in Security Markets, Economics Letters, 1998a, 59 (2), pp. 249-254.

14. Gencay R., The Predictability of Security Returns with Simple Technical Trading Rules, Journal of Empirical Finance, 1998b, 5 (4), pp. 347-359.

15. Granger C. and Morgenstern O., Spectral Analysis of New York Stock Market Prices, Kyklos, 1963, 16, pp. $1-27$.

16. Hansen, Peter, A Test for Superior Predictive Ability, Journal of Business and Economic Statistics, 2005, Vol. 23, pp. 365-380.

17. Hudson R., Dempsey M., and Keasey K., A Note on weak Form of Efficiency of Capital Markets: The Application of Simple Technical trading Rules to UK Stock Prices- 1935 to 1994, Journal of Banking and Finance, 1996, (20), pp. 1121-1132.

18. Jensen M. and Benington G., Random Walks and Technical Theories: Some Additional Evidence, Journal of Finance, 1970, 25, pp. 469-82.

19. Knez P.J. and Ready M.J., Estimating the Profits from Trading Strategies Review of Financial Studies, 1996, 9, pp. 1121-64.

20. Kroner, K., Comments on: Do the profits from Technical trading Rules Reflect Inefficiencies?, mimeo, Wells Fargo Nikko Investment Advisors Advanced Strategy Group, San Francisco 1995.

21. Kwon K. and Kish R., (2002). Technical Trading Strategies and Return Predictability: NYSE, Applied Financial Economics, 2002, 12, pp. 639-53.

22. Larson A., Measurement of Random Process in Futures Prices, Food Research Institute, 1960, 1, pp. 31324.

23. Maillet B. and Michel T., Further Insights on the Puzzle of Technical Analysis Profitability, The European Journal of Finance, 2000, 6, pp. 196-224.

24. Mandelbrot B., The Variation of Certain Speculative Prices, Journal of Business, 1963, 36, pp. 394-419.

25. Mills T.C. and Coutts J.A., Calender effects in the London Stock Exchange FT-SE Indices, European Journal of Finance, 1995, 1, pp. 79-93.

26. Osborne M., Periodic Structure in the Brownian Motion of Stock Prices, Operations Research, 1962, 10, 345-79.

27. Pring M.J., Technical Analysis: Explained, McGraw-Hill Co., 1991.

28. Pruitt S. and White R., The CRISMA Trading System: Who Says Technical Analysis Can't Beat the Market? Journal of Portfolio Management, 1998, 14, (3), pp. 55-58.

29. Raj M. and Thurston D., Effectiveness of simple technical trading rules in the Hong Kong futures markets, Applied Economics Letters, 1996, 3, pp. 33-36.

30. Ratner M. and Leal R.P.C., Test of Technical Trading Strategies in the Emerging Equity Markets of Latin America and Asia Journal of Banking and Finance, 1999, 23 (1), pp. 1887-1905.

31. Ready M., Profits from Technical Trading Rules, Financial Management, Autumn 2002, pp. 43-61.

32. Shleifer A., Inefficient Markets: An Introduction to Behavioral Finance. Oxford University Press, 2000.

33. Sullivan, R., Allan Timmermann, and Halbert White, Data-Snooping, Technical Trading Rule Performance, and the Bootstrap, Journal of Finance, 1999, Vol. 54, No. 5, pp. 1647-1691.

34. Szakmary A., Davidson W.N., and Schwarz T.V., Filter Tests in Nasdaq Stocks, The Financial Review, 1999, 34, pp. 45-70.

35. Taylor M. and Allen H., The Use of Technical Analysis in the Foreign Exchange market, Journal of International Money and Finance, 1992, 11, pp. 304-314.

36. Van Horn J.C. and Parker G.C., The Random Walk Theory: an Empirical Test, Financial Analyst Journal, 1967, 23, pp. 87-92.

37. White, Halbert, A Reality Check for Data Snooping, Econometrica, 2000, Vol. 68, No. 5, pp. 1097-1126. 